While unable to explain the phenomenon, it seems to us to have been a pressure symptom, as it occurred only the last week prior to the opening of the abscess, and ceased when the pressure was relieved.

Neither are the conclusions of Dr. Cushing borne ont " that such cases are sure to terminate fatally, unless by opening and counter-opening, a free drainage and disinfection can be carried out."

\section{THE OPTICIAN AND OPHTHALMOLOGY.}

BY GHORGE; M. GOULD, II.D.,

OPHTHALMOLOGIST TO THE PHILADELPHA HOSPITAL, FHILADELPIIT, ra.

The paragraph by Mr. Henry A. Riley, in THE JoURNAI of May 2, entitled Cosmetics and Spectacles in Court, is one of a thousand illustrations constantly reappearing with sorry monotony, of the fact that when a layman tries to say anything about medicine, he, with the most delicious unconsciousness, takes the side of ignorance and untruth, makes a mess of what he tries to say, and if his words have any weight he injures the cause of scientific medicine. It is a strange fatality akin to that of the success of the patent medicine man, and the enthusiastic acceptance by otherwise intelligent men of the impudent nonsense of homceopathy, faith cure, etc. Mr. Riley's words are few, but as representative of the half-formed opinion of perhaps many others, they should have been excluded from the pages of a journal caring for scientific medical progress, and hence require a dozen words of contradiction.

The first sentence is true, but not as supposed by the gentleman. The optician does "hold a doubtful position in regard to the practice of medicine," and it is because homœopathy holds such a position, and because supposedly intelligent people encourage the continuance of this doubtful position, go to an optician who knows nothing about this work for correction of optical defects of the eye, instead of going to one who with the study of a lifetime can learn but a small part of the desirable knowledge on the subject. The "doubtful position" should be ended at once by the enaction of laws on the "narrow, technical theory" that your correspondent tells us the French courts have found right. Until that is done opticians will go on ruining eyes and health, as all oculists have bitter experience almost daily in trying to undo and correct the injury done their patients who have first passed through the hands of the optician.

If he furnishes a customer glasses to cure errors in sight-if he investigates the troubles of the eye, if he determines the errors in refraction and if he prescribes a combination of lenses such as will remedy the affection, etc. The gentleman evidently never heard of the Teutonic maiden who, while drawing beer, fell into a delightful revery, imagining all the years of splendor and happiness that would follow if she should marry the Prince. In the meantime the beer filled the pitcher and ran all over the floor.

The trouble all lies in the if. In order to be perfectly safe, and also to have a loophole to crawl out of if some ignoramus with fiery eyes avers that he can do it, I will say that there is but one optician in the United States who can "give a customer glasses to cure errors in sight," or who is competent to "determine errors of refraction and prescribe a combination of lenses such as will remedy the affection." There is only one optician who can do this; the other ten thousand cannot do it.

The limit of the ridiculous is finally reached in the very amusing supposition that "the optician may be a physiologist." This bit of fustian spoken before a convention of opticians would certainly be considered the joke of the day. It is too absurd to answer. If we seek the fundamental reasons for the delusion into which such logicians as your correspondent fall, we find them somewhat as follows:

I. A complete misconception on the part of the general public, and too often on the part of some general physicians, as to the rôle of eyestrain in our modern life. Without a medioal education (and with it the optician would necessarily cease to be an optician), the spectacle-vendor cannot know anything of the pathological relations to the eye and the general system. The eye, it is true, is a camera obscura, but it is a living, not a dead or mechanical, one. Every pair of lenses worn by every person in the world has a medical and pathological significance. This, to be sure, seems to the laity an outrageous exaggeration, but it is la vraie verité.

2. The same mediævalism of logic would deny the medical profession a locus standi or justification of existence. If the optician can do all it is said he may do, then the doctor should hand his diploma to the pharmacist and go out of business; because the druggist, as a general rule, is far and away more competent to prescribe the proper drugs in a case of disease than the optician is to prescribe the proper glasses. 'That may also seem an exaggerated statement, and again it is very truth.

3. It is a sneaking, ill-concealed belief on the part of many that this opposition on the part of "allopaths," "the old school," "the blue-mass old fogies," to quackery of all forms, to advertisers, to prescribing druggists and prescribing opticians, is a matter of low cunning, self-interest and envy. Those who secretly harbor such thoughts or feelings simply illustrate their inability to perceive facts correctly. They are victims of their own vanity.

4. If to opticians is to be given the function of 
prescribing for refractive errors, the law should require of them, as it does of druggists, an education in their calling, a diploma that they are opticians, if not "physiologists," "pathologists," etc. Viewing the eye simply as a dead camera obscura, as having no other laws than optic laws, I have never seen a pair of glasses prescribed by an optician that were correct. I have had hundreds of suffering patients abused by the optician's supposed ability to prescribe, and never was a single pair of lenses correct optically speaking. They did not neutralize the patient's optical error. There is one optician, of course, who never makes these mistakes. As a matter of fact, with the one exception, opticians enter their calling either from the jewelry business or from the work-bench of the spectacle-maker and lensgrinder. Neither one of these callings, honorable enough indeed in themselves, necessarily imply an education in the laws of optics or the physiology and pathology of the eye.

5. Not only do all errors of refraction have medical and pathological significance, but if the optician is to treat all errors of refraction, he must perforce be a physiciau; because many diseases, most serious and dangerous ones too, can only be recognized by a physician, are not recognized by the patient as other than a call for spectacles, and could not be recognized by the optician. Every oculist has had instances of glaucomatous patients going to the optician for spectacles. As the disease progresses changes in the spectacles must frequently be made, until finally blindness is the walking monument of the non-existence of the " narrow technical theory" of the French courts, and the dominance of the "broader principle of legal construction" your correspondent hopes will have sway here. Gott bewahr!

It seems doubly strange to hear an intelligent gentleman arguing in this way in the face of the fact that the best opticians are ashamed of the hypocrisy and the wrong they are forced to do by the competition of unprincipled spectacle-vendors. An optician of any intelligence and honesty knows he does wrong in prescribing glasses. Even the worst of them are vaguely conscious of the fact. The better class will not prescribe except in cases of presbyopia, and even then free their consciences by advice to go to the ophthalmologist instead. The very highest class of opticians, men of conscience and intellect, will never sell a pair of spectacles except upon a physician's prescription. In this direction lies the elevation of the optician's profession, scientific and humane progress; in the way counseled by your correspondent lies the degradation of the optician's profession, and a return to mediævalism in medicine.

\section{AMERICAN MEDICAL TEMPERANCE ASSOCIATION.}

BY T. D. CROTHERS, M.D., HARTFORD, CONA.

This Association was organized at Washington, May 7,1891 , in pursuance to call by Dr. N. S. Davis, of Chicago, Ill., inviting all persons interested to meet and confer on the need of such an association. Sixty-one physicians were enrolled as original members, and a constitution and by-laws adopted, a board of officers elected, and thus a new medical organization was auspiciously started.

The purpose and object of this new society is outlined in the following statement offered by Dr. Davis:

"The object of this Association is to advance the practice of total abstinence in and through the medical profession, and to promote investigation as to the action of alcohol in health and disease, and it aims at being a bond of union among medical abstainers scattered all over our country. It admits as members regular medical practitioners who are practical abstainers from all alcoholic liquors as beverages. Members are not required to sign any pledge, but if such for any reason cease to become total abstainers it is expected that they will withdraw from the Association. The liberty of members to prescribe alcohol is entirely uncontrolled."

From this it will be apparent that the central purpose of this society is to study and investigate the action of alcohol as both a beverage and medicine. The only qualification required is to be a regular medical practitioner, and total abstainer from alcohol as a beverage. It will be apparent that the last qualification is more or less a scientific necessity for good work in this field. It is assumed rightly, that all physicians interested in this problem of alcohol should approach it from the scientific side alone, unbiased by any personal considerations of custom or habit, political or religious belief, with no object other than to ascertain the facts concerning alcohol, irrespective of all possible conclusions. This is the spirit and purpose of the Association.

In England a similar association composed of members of the British Medical Society has been in existence many years. Their regular meeting occurs at the same time with the British Medical Association, and the value and usefulness of their work is recognized in all scientific circles. In this country a society called the Association for the Study and Cure of Inebriety has been in existence for twenty years. It is composed largely of specialists and persons engaged in treating inebriety as a disease. While it has done grand work, and built up a very suggestive literature through its Journal of Inebriety, it has not taken up the popular medical discussion of alcohol, which this new society proposes to do. These 